\title{
Analyses of tularemia cases and their long-term results
}

\author{
Udurgucu, H. ${ }^{1 *}$, Sagmak Tartar, A. ${ }^{1}$, Ozer Balin, S. ${ }^{1}$, Akbulut, A. ${ }^{1}$, Demirdag, K. $^{1}$, Kaygusuz, I. ${ }^{2}$ \\ ${ }^{1}$ Department of Infectious Diseases and Clinical Microbiology, School of Medicine, FKrat University, ElazKg\%, Turkey \\ 2Department of Otorhinolaryngology, School of Medicine, FKrat University, ElazKo, Turkey \\ *Corresponding author: hudurguxu@gmail.com
}

\section{ARTICLE HISTORY}

Received: 27 May 2020

Revised: 8 October 2020

Accepted: 9 October 2020

Published: 25 March 2021

\begin{abstract}
Tularemia is a zoonotic disease and endemic in the northern hemisphere. The aim of this study was to evaluate the epidemiological, clinical and laboratory characteristics of tularemia patients, and to re-analyze their lymphadenopathy during the follow-up. The patients who were diagnosed with tularemia were reviewed. They were invited for the long term, physical and radiological evaluations. $69.8 \%$ patients had lived in rural areas. $54.7 \%$ patients were associated with animal husbandry, the $18.9 \%$ had contact with rodents. The most common form was the glandular type (62.3\%). The frequency of granulomatous lymphadenitis was significantly higher in patients diagnosed later than 30 days from the onset of symptoms. Lymphadenopathy was undetectable in $61.5 \%$ patients, its severity was reduced in $38.4 \%$ patients compared to its state at the admission. In rural areas, avoiding contact with wild animals can ensure the protection from the pathogen. Public communities should be made aware of the disease.
\end{abstract}

Keywords: Tularemia, Francisella tularensis, Iymphadenopathy, Outcome.

\section{INTRODUCTION}

Tularemia is a zoonotic disease and endemic in the northern hemisphere. The gram-negative coccobacillus Francisella tularensis causes this disease (Ellis et al., 2002). It is a facultative intracellular pathogen that mostly proliferates in host macrophages (Pechous et al., 2009). F. tularensis is endemic also in Turkey, and infection occurs via several routes and results in different clinical syndromes (Gotschlich \& Berkin, 2007). In general, laboratory workers, farmers and gardeners are at a higher risk of contacting with tularemia.

Clinical symptoms vary from asymptomatic disease to septic shock and death, depending on the infecting strain, site of infection, bacterial load, and the host immune status (Penn, 2010). The most common route of the disease transmission is contact with infected animals and ticks, and that in our country is the intake of contaminated natural or non-chlorinated water (Gürcan et al., 2004; Willke et al., 2009).

The diagnosis of tularemia is usually given lately because it is seen with lymphadenopathy; it is confused with nonspecific laboratory findings and nonspecific pathological findings; and it is not considered usually in differential diagnosis. The epidemiology of the cases may change over time and the incidence of the clinical forms of the tularemia may change accordingly. In this study, we aimed to evaluate tularemia cases in this respect and compare them with regional and world literature. The aim of this study was to evaluate the epidemiological, clinical and laboratory characteristics of tularemia patients, and reanalyze their physical conditions and lymphadenopathy during the follow-up.

\section{MATERIALS AND METHODS}

Study design, settings and ethics

This study has been conducted in accordance with the principles of the Helsinki Declaration and approved by the local Institutional Review Board (date of the approval: 04/05/ 2017, number of the approval: 08/20).

Patients who were diagnosed with tularemia in the National reference laboratory and monitored in our clinic between 2011 and 2017 were retrospectively reviewed. All patients who were diagnosed with tularemia were included in the study. Their age, sex, epidemiologic anamnesis, symptoms, physical condition, complete blood count, creactive protein, erythrocyte sedimentation rate, tularemia polymerase chain reaction, Micro-agglutination titration (MAT), imaging, pathology results, treatment regimens and follow-ups were recorded. In addition, all patients were invited for the second time. The patients were contacted by telephone and invited to our outpatient clinic for the long term, physical, laboratory and radiological evaluations. All patients provided signed consents after they agreed to participate in the study.

Patients who could not reach out from their recorded phone numbers and who did not agree to participate in the 
study excluded. In addition, patients who had another infectious focus was detected in the examination during their admission to the hospital was excluded.

\section{Statistical analysis}

Data were analysed using the IBM Statistical Package for Social Sciences v22 (SPSS, Inc., Chicago, IL, USA). The variables were investigated using visual (histograms, probability plots) and analytic methods (Shapiro-Wilk's test) to determine whether they were normally distributed. We presented descriptive statistics such as frequencies for categorical variables, means ( \pm standard deviations) and medians (interquartile range (IQR)) for continuous variables according to the results of a normality test. $P$ values of $<0.05$ were considered statistically significant for all analysis. Pearson Chi-square and Fisher Exact tests were used to compare categorical variables. In order to determine the correlation between two continuous variables, spearman's rank correlation analysis were used for asymmetric variables.

\section{RESULTS}

A total of 53 tularemia patients, $26(49.1 \%)$ male and 27 $(50.9 \%)$ female, with median age of 23 years (interquartile range was $17-41$ years) were followed. Five patients $(9.4 \%)$ had chronic diseases (one had hypertension, one asthma, one chronic hepatitis $B$ and two had diabetes mellitus). In addition, two patients were pregnant. Thirty-seven (69.8\%) patients had lived in rural areas and $16(30.2 \%)$ were in the city. In addition, 29 (54.7\%) patients were associated with animal husbandry, 10 (18.9\%) had contact with mice and rabbits, and $8(15.1 \%)$ hunted animals. We did not have any patient with tick contact. Furthermore, 38 patients $(71.7 \%)$ consumed chlorinated water. The median time between the onset of complaint and admission to our clinic was 21 days (IQR: 15-60 days).

The glandular form was detected most frequently among the patients $(33 ; 62.3 \%)$, while $19(35.8 \%)$ cases were oropharyngeal, and $1(1.9 \%)$ was ulceroglandular. The complaints of the patients upon admission and the findings of physical examinations are given in Table 1. Radiological imaging was performed for 46 (86.8\%) patients. Lymphadenopathy was found in 36 (78.3\%) patients, abscess in $10(13 \%)$ patients, lymphadenopathy and abscess in 4 (8.7\%) patients. When patients are examined according to lymphadenopathy localization, cervical 26 (49.1\%), submandibular $15(28.3 \%)$, submandibular and cervical 7 (13.2\%), axillary $1(1.9 \%)$, inguinal $1(1.9 \%)$, parapharyngeal $1(1.9 \%)$ and other areas $2(3.8 \%)$ detected. Lymphadenopathy was unilateral in 31 patients (58.5\%) and bilateral in 21 patients $(39.6 \%)$. Surgical drainage was performed for $32(60.3 \%)$ patients and fine-needle aspiration biopsy in $6(11.3 \%)$ patients, while spontaneous drainage was observed in 2 cases $(3.7 \%)$. Thirty-eight (71.7\%) patients underwent pathological examinations. Findings reported as; suppurative inflammation 19 (50\%), granulomatous inflammation 8 (21.1\%), non-diagnostic material 7 (18.4\%), nonspecific lymphadenitis 2 (5.3\%), reactive lymphoid hyperplasia $1(2.6 \%)$ and coccobacillus-shaped microorganism 1 (2.6\%). The incidence of granulomatous lymphadenitis was significantly higher in patients diagnosed later than 30 days, compared to the patients diagnosed earlier ( $p: 0.032$ ).

MAT showed positivity of $1 / 1280$ in $20(39.2 \%)$ patients, $1 / 640$ in $14(27.5 \%)$ patients, $1 / 320$ in $9(17.6 \%)$ patients, and $1 / 160$ in $8(15.7 \%)$ patients. Bacterial culture was performed for nine patients and growth was seen only in one sample. There was a very weak negative correlation between the duration of patient admission and their MAT (rho:- 0.05, P > $0.05)$. The results of the laboratory tests of the patients at the time of admission are shown in Table 2.

For treatment, doxycycline was given to 18 patients (34\%), streptomycin to $14(26.4 \%)$, ciprofloxacin to $9(17 \%)$, and a combination of streptomycin and doxycycline to 12 patients $(20.8 \%)$. A total of $47(88.6 \%)$ patients had received beta-lactam antibiotic treatment before the diagnosis of tularemia. The treatment durations were 14 days for 41 (77.4\%) patients and 21 days for 12 (22.6\%) patients. One patient who received a 14-day course of doxycycline had a recurrence, and thus underwent another surgical drainage. He was cured after a 14-day regimen of ciprofloxacin.

Twenty-six (49\%) patients agreed to participate in the long-term follow-up. There were no complaints and physical examination findings were also normal. Ultrasonography (US) was performed for lymphadenopathy dimensions, and was undetectable in $16(61.5 \%)$ patients, and reduced in $10(38.4 \%)$ patients compared to the state at the time of admission. There was no significant difference between the clinical form of tularemia, duration of treatment, surgical drainage, delay in diagnosis, and loss or shrinkage of lymphadenopathy due to pathology $(p>0.05)$ (Table 3$)$.

Table 1. Symptoms and findings of patients according to clinical presentation

\begin{tabular}{|c|c|c|c|c|}
\hline & Glandular n (\%) & Ulceroglandular n (\%) & Oropharyngeal n (\%) & Total n (\%) \\
\hline Sore throat & $9(27.2)$ & 0 & $17(89.4)$ & $26(49.1)$ \\
\hline Weakness & $17(51.5)$ & 0 & 15 (78.9) & $32(60.4)$ \\
\hline Fever & $15(45.4)$ & 0 & $14(73.6)$ & $29(54.7)$ \\
\hline Muscle pain & $11(33.3)$ & 0 & $11(57.8)$ & $22(41.5)$ \\
\hline Headache & $3(9)$ & 0 & $2(10.5)$ & $5(9.4)$ \\
\hline Nausea/vomiting & $3(9)$ & 0 & $3(15.7)$ & $6(11.3)$ \\
\hline Chills & $14(42.4)$ & 0 & $11(57.8)$ & $25(47.2)$ \\
\hline Anorexia & $13(39.3)$ & 0 & $11(57.8)$ & $24(45.3)$ \\
\hline Weight loss & $7(21.2)$ & 0 & $3(15.7)$ & $10(18.9)$ \\
\hline Lymphadenopathy & $33(100)$ & $1(100)$ & $18(94.7)$ & $52(98.1)$ \\
\hline Rash & $1(3)$ & $1(100)$ & $3(15.7)$ & $5(9.4)$ \\
\hline Tonsillopharyngitis & $2(6)$ & 0 & $17(89.4)$ & $19(35.8)$ \\
\hline Hepatomegaly & $1(3)$ & 0 & $2(10.5)$ & $3(5.6)$ \\
\hline Splenomegaly & 0 & 0 & $1(5.2)$ & $1(1.8)$ \\
\hline Conjunctivitis & $1(3)$ & 0 & $1(5.2)$ & $2(3.7)$ \\
\hline
\end{tabular}


Table 2. Various laboratory test values on the admission day of patients

\begin{tabular}{lcc}
\hline $\mathrm{n}: 53$ & Median (interquartile range) & Reference ranges \\
\hline WBC $\left(\mathrm{mm}^{3}\right)$ & $9600(7800-11000)$ & $3800-8600$ \\
Neutrophil $\left(\mathrm{mm}^{3}\right)$ & $5700(4600-6600)$ & $2100-6100$ \\
ESH $(\mathrm{mm} / \mathrm{h})$ & $34(17-49)$ & $0-20$ \\
CRP $(\mathrm{mg} / \mathrm{L})$ & $8(3-21)$ & $0-5$ \\
Plt $(/ \mathrm{hL})$ & $350.000(280.000-400.000)$ & $140.000-360.000$ \\
Urea $(\mathrm{mg} / \mathrm{dl})$ & $28(21-31)$ & $10-50$ \\
Creatin $(\mathrm{mg} / \mathrm{dl})$ & $0.6(0.4-0.8)$ & $0.6-1.2$ \\
AST $(\mathrm{U} / \mathrm{L})$ & $28(20-35)$ & $5-40$ \\
ALT $(\mathrm{U} / \mathrm{L})$ & $30(19-38)$ & $5-40$ \\
\hline
\end{tabular}

$\mathrm{WBC}=$ white blood cell; $\mathrm{CRP}=\mathrm{C}$-reaktif protein; $\mathrm{Plt}=$ platelet $; \mathrm{AST}=$ Aspartate aminotransferase; $\mathrm{ALT}=$ Alanine aminotransferase.

Table 3. Relation of long-term lymphadenopathy status to various parameters

\begin{tabular}{|c|c|c|c|}
\hline & \multicolumn{2}{|c|}{ Lymphadenopathy } & \multirow{2}{*}{$\mathrm{P}$} \\
\hline & Shrinks & Disappeared & \\
\hline \multicolumn{4}{|l|}{ Treatment duration } \\
\hline 14 days (n: 21) & $14(66.7)$ & $7(33.3)$ & 0.274 \\
\hline 21 days (n: 5) & $3(60)$ & $2(40)$ & \\
\hline \multicolumn{4}{|l|}{ Treatment } \\
\hline Ciprofloxacin & $1(14.3)$ & $6(85.7)$ & \\
\hline Doxycycline & $5(55.6)$ & $4(44.4)$ & \\
\hline Streptomycin & $3(50)$ & $3(50)$ & \\
\hline Streptomycin + doxycycline & $1(25)$ & $3(75)$ & \\
\hline \multicolumn{4}{|l|}{ Drainage } \\
\hline Yes & $7(58.8)$ & $10(41.2)$ & 0.517 \\
\hline No & $3(33.3)$ & $6(66.7)$ & \\
\hline \multicolumn{4}{|l|}{ Tularemia form } \\
\hline Oropharyngeal & $7(53.8)$ & $6(46.2)$ & 0.107 \\
\hline Glandular & $3(23.1)$ & $10(76.9)$ & \\
\hline \multicolumn{4}{|c|}{ Time between diagnosis and complaint } \\
\hline $1-30$ days & $6(57.1)$ & $8(42.9)$ & 0.464 \\
\hline$<30$ days & $4(33.3)$ & $8(66.7)$ & \\
\hline \multicolumn{4}{|l|}{ Application year } \\
\hline 2011-2012 & $1(12.5)$ & $7(87.5)$ & \\
\hline 2013-2014 & $5(55.6)$ & $4(44.4)$ & \\
\hline 2015-2016 & $3(37.5)$ & $5(62.5)$ & \\
\hline 2017 & $1(100)$ & - & \\
\hline \multicolumn{4}{|l|}{ Pathology } \\
\hline Granulomatous lymphadenitis & $4(57.1)$ & $3(42.9)$ & \\
\hline Nonspecific lymphadenitis & $1(20)$ & $4(80)$ & \\
\hline Suppurative lymphadenitis & $2(22.2)$ & 7 (77.8) & \\
\hline
\end{tabular}

\section{DISCUSSION}

The frequency of tularemia has increased significantly due to climate change, and re-distribution of reservoirs and vector populations. In recent years, it has become an important zoonotic disease in Turkey (Akalin et al., 2009). The first cases of tularemia in our country were identified in an outbreak in the military garrison of Luleburgaz in 1936. In the following years, sporadic cases and small-point source epidemics were reported from different regions (Gotschlich \& Berkin, 2007; Celebi et al., 2014) In our study, $50.9 \%$ of the patients were female and the median age was 23 years. Akalin et al. (2009) reported that all age groups and both sexes are equally affected by tularemia, while other reports from our country cite an incidence rate of $54 \%-80 \%$ in women (Ulu-Kilic et al., 2013; Erdem et al., 2014). A study in Germany reported that tularemia is seen more common in men than in women (Faber et al., 2018). The difference in the sex ratios is likely due to the regional and cultural differences.

The most common route of tularemia infection worldwide is contact with infected animals and ticks. In Turkey, however, infection is mostly transmitted by the consumption of contaminated water. Therefore, oropharyngeal tularemia is the most frequently diagnosed clinical form of this disease in our country (Erdem et al., 2014; KKIKc, 2014). This is consistent with the observation that $F$. tularensis can survive for several months in water (Helvaci et al., 2000). In our study, $71.7 \%$ of the patients were consuming municipal water and the glandular form was most commonly detected. Other studies conducted in Turkey have also found the most frequent form of tularemia to be glandular (Leblebicioglu et al., 2008). Awareness regarding clean water and disinfection along with regular inspection of municipal water have likely reduced the frequency of oropharyngeal cases over time. In addition, $69.8 \%$ of our patients lived in rural areas and $54 \%$ of them worked in animal husbandries. According to other reports, tularemia is frequently seen in rural areas (Karadenizli et al., 2005; Akalin et al., 2009).

The initial symptoms of tularemia are often very similar to the common cold, such as myalgia, arthralgia, chills, weakness, loss of appetite, weight loss and sudden onset of fever accompanied with headache (Helvaci et al., 2000). Systemic findings may include pneumonia, typhoidal tularemia, and fever without localized findings (Richard \& Gordon, 2010). In our country, $92 \%-100 \%$ of tularemia cases have neck swelling, 66\%-90\% have a fever lasting 3-10 days and 58\%-92\% have a sore throat (Helvaci et al., 2000; Erdem et al., 2014). In the acute phase of the disease, $88.6 \%$ of our patients received beta-lactam group antibiotic therapy at outer centers. They were admitted to our clinic after the onset of neck swelling, and when their complaints did not recede. This shows that awareness of primary care for tularemia is inadequate among the physicians, and they should be trained to deal with this condition. Lymphadenopathy was the most common finding among our patients, consistent with $85 \%-100 \%$ incidence rate in other studies (Helvaci et al., 2000; Meric et al., 2008). Cervical lymphadenopathy is the most frequently observed form in our country, and was detected in $49.1 \%$ of the patients who underwent imaging (Ulu-Kilic et al., 2013; Erdem et al., 2014). One report indicates higher frequency of left-sided lymphadenopathy (Maurin et al., 2011). In our study, $58.5 \%$ of the Iymphadenopathies were unilateral and right-sided for $51.6 \%$ of those cases.

Tularemia can be confused with other diseases due to the lack of specific clinical symptoms and findings as well as laboratory findings. As per the guidelines of the World Health Organization, at least one MA titer above 1:128 or a 4-fold increase of titer in serum samples at 14-day intervals confirm tularemia. Francisella tularensis is difficult to isolate in culture; although one study reported $84 \%$ serologically positive cases, the pathogen could be isolated in only $10 \%$ of the cases (Richard \& Gordon, 2010). Helvaci et al. (2000) were able to isolate the pathogen in 10 of 205 patients. We detected positive agglutination in 52 patients, but positive culture was detected for only one of the nine patients tested. During the early stages of tularemia, i.e., the first two weeks of infection, polymerase chain reaction (PCR) detection should be considered due to the low MA titres (Ellis et al., 2002). In the lymph node aspiration samples of three cases, positive detection was made for Francisella tularensis via PCR. The antibody titers peak six weeks after the onset of 
symptoms, and fall by two or three months after treatment (Ozdemir et al., 2007; Tatman Otkun et al., 2011). In endemic areas, MAT can be easily used in the differential diagnosis of tularemia for patients with a sore throat, fever, and lymphadenopathy, but due to low titers in the early stages of infection, PCR should be considered (Tärnvik \& Chu, 2007). In our study, there was no significant association of MA titers of the patients to their time of admission.

Histopathological characterization of lymphadenomegaly in tularemia is usually limited due to the small number of cases (Leblebicioglu et al., 2008; Ulu-Kilic et al., 2013; Strehl et al., 2014). Reactive changes not detected in necrosis were reported mostly in the initial stages. After the second week, epitheloid cell reactions or apse formations without epithelioid cell reactions are seen. Large numbers of small epitheloid granulomas containing necrotic zones in the middle appear within 2-6 weeks, along with multicellular giant cells. After the fourth week, caseous necrosis is usually detected (Asano, 2012). Tularemia is histopathologically characterized by the granulomatous lesions containing focal caseous necrotic areas. Erdem et al. (2014) detected granulomatous inflammation in 56\% of 1034 tularemia patients. Due to the granulomatous and suppurative lymphadenitis formation, it is essential to differentiate tularemia from other infectious and non-infectious diseases with similar presentation. For instance, granulomatous lymphadenitis is often confused with tuberculosis due to the endemicity of tuberculosis in our country. In our study, suppurative inflammation was detected in $50 \%$ of the patients who underwent pathological examination. The incidence of granulomatous lymphadenitis was higher in patients who were admitted for longer than 30 days. However, no caseous necrosis was detected in these patients. Considering the patients admitted with sporadic lymphadenopathy, nonevaluation of tularemia causes these patients to receive different diagnosis, treatment and to be examined from the malignancies aspects such as lymphoma. In the differential diagnosis of granulomatous lymphadenitis cases, tularemia should also be considered.

Abortion and intrauterine death due to tularemia infection are seen in sheep. Data on maternal complications in humans, however, is very limited due to the rarity of identifying this disease (Yeşilyurt et al., 2013). Although the usage of gentamicin and ciprofloxacin during pregnancy has not been approved by Food and Drug Administration (FDA), it is recommended by the World Health Organization (WHO) and the United Kingdom Health Protection Agency as the first choice (World Health Organization, 2007). Successful treatments with gentamicin and ciprofloxacin have been reported during pregnancy (Yeşilyurt et al., 2013). In this study, 25-weeks and 12-weeks pregnant patients were treated with gentamicin and ciprofloxacin, respectively, without any complications. No pathological signs were detected during the postpartum period and long-term follow-up of the newborns.

Early treatment of tularemia increases the chances of recovery, which are reduced even if the treatment is given in 23 weeks, resulting in the development of lymph node suppuration (Helvaci et al., 2000; Meric et al., 2008). In patients with lymphadenopathy who do not receive or respond to specific treatment for tularemia, fluticuation and suppuration develop, requiring surgical drainage (Helvaci et al., 2000; Meric et al., 2008). It was performed in $32(60.3 \%)$ patients who were admitted 15 days after the onset of complaints, and were thus indicated for surgical drainage. Most cases of cervical lymphadenitis are resolved by effective medical treatment. Abscess formation may also occur in some patients, and can be removed by aspiration. In case of recurrence, surgical drainage can be performed with a small incision. In patients with caseification, lymph node excision may be performed (Erdem et al., 2014). We performed laparoscopic (LAP) excision in one (1.8\%) patient. Lymphadenopathy responds slowly to treatment, and full recovery may require up to four months (Maurin et al., 2011). Although the lymph ganglia are often sterile after treatment, a relatively long convalescence period (2-6 months, may also last up to three years) is needed for suppuration free recurrence of lymphadenopathy (Dennis et al., 2001). We contacted 26 (49\%) of our patients and monitored lymphadenopathy with US. The mass was lost in 16 (61.5\%) patients, and reduced in $10(38.4 \%)$ patients. The persistence of lymphadenopathy was not considered a failure of treatment. In our country, no deaths or major complications have been reported in tularemia cases (Helvaci et al., 2000; Meric et al., 2008; Erdem et al., 2014), and similar results were seen in our study.

\section{CONCLUSIONS}

The incidences of tularemia have become more frequent worldwide and in our country in recent years, and present with different clinical symptoms. It can be confounded with other infectious and non-infectious diseases, which causes delays in diagnosis and economic losses. Avoiding vector and reservoir contact plays an important role in the disease control. Factors such as global warming or migration of ticks with birds cannot be controlled but human contact with vector and reservoirs can be avoided. In rural areas, avoiding direct contact with dead and wild animals by using protective clothing and repellents can ensure protection from the pathogen. Hygienic preparation of food and beverages, proper chlorination of water and well-cooked meats are also important in tularemia prevention. Public community should be informed for the awareness about the disease and education programs should be organized.

\section{Conflict of interest}

The author declares that they have no conflict of interests.

\section{REFERENCES}

Akalin, H., Helvaci, S. \& Gedikogolu, S. (2009). Re-emergence of tularemia in Turkey. International Journal of Infectious Diseases 13(5): 547-551. https://doi.org/10.1016/j.ijid. 2008.09.020

Asano, S. (2012). Granulomatous lymphadenitis. Journal of Clinical and Experimental Hematopathology 52(1): 1-16. https://doi.org/10.3960/js/rt.52.1

Celebi, B., KKIKç, S., Yeşilyurt, M. \& Acar, B. (2014). Evaluation of a newly-developed ready-to-use commercial PCR kit for the molecular diagnosis of Francisella tularensis. Mikrobiyoloji Bulteni 48(1): 135-142.

Dennis, D.T., Inglesby, T.V., Henderson, D.A., Bartlett, J.G., Ascher, M.S., Eitzen, E., Fine, A.D., Friedlander, A.M., Hauer, J., Layton, M., Lillibridge, S.R., McDade, J.E., Osterholm, M.T., O'Toole, T., Parker, G., Perl, T.M., Russell, P.K., Tonat, K. \& Working Group on Civilian Biodefense (2001). Tularemia as a biological weapon: medical and public health management. Journal of the American Medical Association 285(21): 2763-2773. https://doi.org/10.1001/ jama.285.21.2763

Ellis, J., Oyston, P.C., Green, M. \& Titball, R.W. (2002). Tularemia. Clinical Microbiology Reviews 15(4): 631-646. https://doi.org/ 10.1128/CMR.15.4.631-646.2002 
Erdem, H., Ozturk-Engin, D., Yesilyurt, M., Karabay, O., Elaldi, N., Celebi, G., Korkmaz, N., Guven, T., Sumer, S., Tulek, N., Ural, O., Yilmaz, G., Erdinc, S., Nayman-Alpat, S., Sehmen, E., Kader, C., Sari, N., Engin, A., Cicek-Senturk, G., ErtemTuncer, G., Gulen, G., Duygu, F., Ogutlu, A., Ayaslioglu, E., Karadenizli, A., Meric, M., Ulug, M., Ataman-Hatipoglu, C., Sirmatel, F., Cesur, S., Comoglu, S., Kadanali, A., Karakas, A., Asan, A., Gonen, I., Kurtoglu-Gul, Y., Altin, N., Ozkanli, S., Yilmaz-Karadag, F., Cabalak, M., Gencer, S., Umut Pekok, A., Yildirim, D., Seyman, D., Teker, B., Yilmaz, H., Yasar, K., Inanc Balkan, I., Turan, H., Uguz, M., Kilic, S., Akkoyunlu, Y., Kaya, S., Erdem, A., Inan, A., Cag, Y., Bolukcu, S., Ulu-Kilic, A., Ozgunes, N., Gorenek, L., Batirel, A. \& Agalar, C. (2014). Evaluation of tularaemia courses: a multicentre study from Turkey. Clinical Microbiology and Infection 20(12): 01042-01051. https://doi.org/10.1111/1469-0691.12741

Faber, M., Heuner, K., Jacob, D. \& Grunow, R. (2018). Tularemia in Germany-A Re-emerging Zoonosis. Frontiers in Cellular and Infection Microbiology 8: 40. https://doi.org/10.3389/ fcimb.2018.00040

Gotschlich, E. \& Berkin T. (2007). 1936 yKIKnda Trakya'da tularemiye ait yapKlan epidemiyolojik ve bakteriyolojik araştKrmalar. Türk Hijyen ve Deneysel Biyoloji Dergisi 64(1): 71-75.

Gürcan, S., Otkun, M.T., Otkun, M., Arikan, O.K. \& Ozer, B. (2004). An outbreak of tularemia in Western Black Sea region of Turkey. Yonsei Medical Journal 45(1): 17-22.

Helvaci, S., Gedikogolu, S., Akalin, H. \& Oral, H.B. (2000). Tularemia in Bursa, Turkey: 205 cases in ten years. European Journal of Epidemiology 16(3): 271-276. https://doi.org/ 10.1023/A:1007610724801

Karadenizli, A., Gurcan, S., Kolayli, F. \& Vahaboglu, H. (2005). Outbreak of tularaemia in Golcuk, Turkey in 2005: report of 5 cases and an overview of the literature from Turkey. Scandinavian Journal of Infectious Diseases 37(10): 712-716. https://doi.org/10.1080/00365540510012125

Kilic, S. (2014). Tularemia: The Pathogen and Epidemiology. Turkiye Klinikleri Journal of Infection Diseases Special Topics 7(2): 52-61.

Leblebicioglu, H., Esen, S., Turan, D., Tanyeri, Y., Karadenizli, A., Ziyagil, F. \& Goral, G. (2008). Outbreak of tularemia: a case-control study and environmental investigation in Turkey. International Journal of Infectious Diseases 12(3): 265-269. https://doi.org/10.1016/j.ijid.2007.06.013

Maurin, M., Pelloux, I., Brion, J.P., Del Banõ, J.N. \& Picard, A. (2011). Human tularemia in France, 2006-2010. Clinical Infectious Diseases 53(10): e133-e141. https://doi.org/ 10.1093/cid/cir612

Meric, M., Willke, A., Finke, E.J., Grunow, R., Sayan, M., Erdogan, S. \& Gedikoglu, S. (2008). Evaluation of clinical, laboratory, and therapeutic features of 145 tularemia cases: the role of quinolones in oropharyngeal tularemia. Acta Pathologica, Microbiologica, et Immunologica Scandinavica 116(1): 66-73. https://doi.org/10.1111/j.1600-0463.2008.00901.x

Ozdemir, D., Sencan, I., Annakkaya, A.N., Karadenizli, A., Guclu, E., Sert, E., Emeksiz, M. \& Kafali, A. (2007). Comparison of the 2000 and 2005 outbreaks of tularemia in the Duzce region of Turkey. Japanese Journal of Infectious Diseases 60(1): 51-52.

Pechous, R.D., McCarthy, T.R. \& Zahrt, T.C. (2009). Working toward the future: insights into Francisella tularensis pathogenesis and vaccine development. Microbiology and Molecular Biology Reviews 73(4): 684-711. https://doi.org/ 10.1128/MMBR.00028-09
Penn, RL. (2010). Francisella tularensis (Tularemia). In: Mandell GL, Bennett JE, Dolin R, editors. Mandell, Douglas, and Bennett's principles and practice of infectious diseases. $7^{\text {th }}$ edition. Philadelphia: Churchill Livingstone, pp.2927-2937.

Richard, F.J. \& Gordon, E.S. (2010). Tularemia. In: Dennis, L.K., Anthony, S.F., editors. Harrison's Infectious Diseases. New York: The McGraw-Hill, pp.552-557.

Strehl, J., Schoerner, C., Hartmann, A. \& Agaimy, A. (2014). Tularämie-Lymphadenitis. Tularemia lymphadenitis. An emerging differential diagnosis of necrotizing granulomatous cervical lymphadenitis. Der Pathologe 35(2): 166-172. https://doi.org/10.1007/s00292-013-1851-5

Tärnvik, A. \& Chu, M.C. (2007). New approaches to diagnosis and therapy of tularemia. Annals of the New York Academy of Sciences 1105: 378-404. https://doi.org/10.1196/ annals.1409.017

Tatman Otkun, M., AkçalK, A., Karadenizli, A., Ozbey, N., Gazel, D., Sener, A., Güçlü, O., TanrKöver, A. \& Otkun, M. (2011). Epidemiological evaluation of a rapidly-prevented tularemia outbreak in Canakkale province, Turkey. Mikrobiyoloji Bulteni 45(1): 48-57.

Ulu-Kilic, A., Gulen, G., Sezen, F., Kilic, S. \& Sencan, I. (2013). Tularemia in central Anatolia. Infection 41(2): 391-399. https://doi.org/10.1007/s15010-012-0355-1

Willke, A., Meric, M., Grunow, R., Sayan, M., Finke, E.J., Splettstößer, W., Seibold, E., Erdogroan, S., Ergonul, O., Yumuk, Z. \& Gedikoglu, S. (2009). An outbreak of oropharyngeal tularaemia linked to natural spring water. Journal of Medical Microbiology 58(Pt1): 112-116. https://doi.org/10.1099/ jmm.0.002279-0

World Health Organization. (2007). WHO Guidelines on Tularemia. Switzerland: World Health Organization. https://www.who.int/csr/resources/publications/ deliberate/WHO_CDS_EPR_2007_7/e/ [Retrieved 12 July 2020]

Yeşilyurt, M., Kiliç, S., Çelebi, B. \& Gül, S. (2013). Tularemia during pregnancy: report of four cases. Scandinavian Journal of Infectious Diseases 45(4): 324-328. https://doi.org/10.3109/ 00365548.2012 .720027 